\title{
Impact evaluation of a school-based oral health program: Kuwait National Program
}

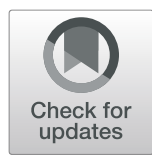

\author{
Aishah Alsumait ${ }^{1 *}$, Mohamed ElSalhy ${ }^{2}$, Sahar Behzadi ${ }^{1}$ Kim D. Raine ${ }^{3}$, Rebecca Gokiert ${ }^{4}$, Ken Cor ${ }^{5}$, \\ Sabiha Almutawa ${ }^{1}$ and Maryam Amin ${ }^{6}$
}

\begin{abstract}
Background: This study evaluated the relationship between enrolment in a school-based oral health prevention program (SOHP) and: 1) children's dental health status and oral health-related quality of life (OHRQoL), and 2) mothers' oral health $(\mathrm{OH})$ knowledge, attitude, practice, and OHRQoL.

Methods: This cross-sectional study, in the Kuwait Capital, included 440 primary school children aged 11 to 12 years and their mothers. Participants were classified into two groups: SOHP and non-SOHP. The SOHP group had been enrolled in the prevention program for at least 3 years: children had twice-a-year applications of fluoride varnish and fissure sealants if needed; mothers had, at least, one oral health education session. The non-SOHP group had negative consents and had not been exposed to the prevention program activities. Dental examinations were performed at schools using portable dental units. Caries experience was determined using the decayed (D/d), missing $(\mathrm{M} / \mathrm{m})$, and filled $(\mathrm{F} / \mathrm{f})$ teeth $(\mathrm{T} / \mathrm{t}) /$ surface $(\mathrm{S} / \mathrm{s})$ indices. Children's OHRQoL was assessed using a selfadministered validated Child Perceptions Questionnaire 11-14 (CPQ $11-14)$. Mothers' OH knowledge, attitude, practice, and OHRQoL were also assessed. After Bonferroni correction, a $p$-value of less than 0.05 was considered statistically significant for caries experience measures while a p-value of less than 0.013 was considered statistically significant for OHRQoL subscales and mothers' OH knowledge, attitude, practice, and OHRQoL.

Results: Mean (SD) DT/dt, DMFT/dmft and DMFS/dmfs were 1.41 (1.66), 2.35 (2.33), and 4.41 (5.86) for SOHP children, respectively. For non-SOHP children, the means were 2.61 (2.63), 3.56 (3.05), and 7.24 (7.78), respectively. The difference between the SOHP and non-SOHP was statistically significant $(p<0.001)$. Children enrolled in the program had a higher number of sealed and restored teeth. No significant differences were found in $C P Q_{11-14}$ scores or subscale scores between the two groups. No significant difference in mothers' OH knowledge, attitude, practices or OHRQOL was found between SOHP and non-SOHP groups $(P>0.013)$.
\end{abstract}

Conclusion: Enrolment in the SOHP prevention services was associated with a positive impact on children's caries level with no significant impact on mothers' knowledge, attitude, practice, or OHRQoL.

Keywords: Children, Caries, Mothers, Knowledge, Oral health quality of life

\section{Background}

Worldwide, dental professionals struggle to improve public oral health. School-based programs have been established to provide prevention services, including oral health, for school-aged children $[1,2]$. These programs can benefit a wide group of children at minimum cost, especially those who are less likely to receive dental care due to economic

\footnotetext{
*Correspondence: alsuamit@ualberta.ca

${ }^{1}$ National School Oral Health Program, Ministry of Health, PO Box No 5338,

22064 Salmiya, Kuwait

Full list of author information is available at the end of the article
}

limitations and limited exposure to fluoride [2]. In fact, using the school as a setting for oral health promotion interventions was recommended in 2002 by the World Health Organization (WHO). Activities in school programs have included oral health education/promotion, supervised tooth brushing, fluoride and fissure sealant application, and/or various treatments. These activities can shape children's health-related beliefs, attitudes, values and behaviors. In addition, evidence suggests that oral health services in childhood can influence a healthy lifestyle into adulthood $[3,4]$. Although school-based oral health education has

(c) The Author(s). 2019 Open Access This article is distributed under the terms of the Creative Commons Attribution 4.0 International License (http://creativecommons.org/licenses/by/4.0/), which permits unrestricted use, distribution, and reproduction in any medium, provided you give appropriate credit to the original author(s) and the source, provide a link to the Creative Commons license, and indicate if changes were made. The Creative Commons Public Domain Dedication waiver (http://creativecommons.org/publicdomain/zero/1.0/) applies to the data made available in this article, unless otherwise stated. 
been found to be effective in promoting oral hygiene and improving oral health knowledge and practices $[5,6]$, there is a research gap in the literature on the impact of multi-approach preventive programs [1].

In 1983, the Kuwaiti government established the School Oral Health Program (SOHP) in the capital region. The program is a partnership between the Kuwaiti Ministry of Health and the Forsyth Institute, Cambridge, U.S.A., in reaction to the $80 \%$ caries rate found in the 1982 national oral health survey [7]. The SOHP was established to provide dental education, prevention, and treatment for children between the ages of 6 and 14 years. These prevention services are offered through mobile clinics at the schools, preventive services, and center-based clinics (See Table 1 for the logic model associated with SOHP). The program provided dental care for approximately 300,000 school children, with $60-70 \%$ of these children receiving preventive (general oral health education, tooth-brushing education services, fluoride varnish, fissure sealants) or therapeutic dental care-treatment in 2004 [7].

The Kuwaiti School Oral Health Program has the following broad goals: (1) reduce the prevalence of dental caries among school children by increasing the proportion of caries-free children; (2) reduce the severity of dental caries; and (3) improve the oral health status among this population through oral health education involving parents, teachers and children [7]. Most of the children enrolled in the program receive fluoride varnish applications, and about half of them have at least one sealed tooth. Around $4000 \mathrm{~h}$ are spent annually on education, including special sessions conducted for children, parents, and teachers in the schools [7].

Oral health-related quality of life (OHRQoL) reflect subjective indicators of oral health status and its impact on various aspects of life [8]. It is based on information provided by individuals. OHRQoL measures provide essential information when assessing the treatment needs of individuals and populations. They are also important for making clinical decisions and evaluating interventions, services, and public health programs $[9,10]$. OHRQoL can be measured using four domains: oral symptoms, functional limitations, social well-being, and emotional well-being. OHRQoL domains are interconnected and affect one another. Dental health status was shown to have a direct impact on children's overall OHRQoL [11].

Four national oral health surveys were conducted by SOHP in 1982, 1985, 1993, and 2001 to determine the dental health status of children aged 5-15 years. The surveys showed no improvement in dental caries incidence in the population $[12,13]$. As these surveys do not differentiate between SOHP enrolled and non-enrolled children, they cannot reflect the effectiveness of the program. The impacts of the SOHP components had not been fully evaluated. Therefore, this study aimed to examine the relationship between enrolment in a school-based oral health program (SOHP) and (1) children's dental health status and Oral Health-Related Quality of Life, and (2) mothers'

Table 1 School prevention and education logic model

\begin{tabular}{|c|c|c|c|c|c|}
\hline Recourses & Activities & Outputs & Short-term outcomes & Intermediate outcomes & Long-term outcomes \\
\hline \multicolumn{6}{|l|}{ Prevention: } \\
\hline $\begin{array}{l}\text { Prevention } \\
\text { team } \\
\text { leader } \\
\text { Prevention } \\
\text { teams: } \\
\text { • Dentists } \\
\text { • } \\
\text { Hygienists } \\
\text { • Dental } \\
\text { Assistants. } \\
\text { Location: } \\
\text { schools }\end{array}$ & $\begin{array}{l}\text { Provide fluoride varnish } \\
(\mathrm{FL}), \text { Fissure sealants (FS) }\end{array}$ & $\begin{array}{l}\text { Children with FL and } \\
\text { FS protection }\end{array}$ & $\begin{array}{l}\text { 1. Increase proportion of the } \\
\text { child population is protected } \\
\text { with FL and FS }\end{array}$ & $\begin{array}{l}\text { Lower incidence of } \\
\text { decay }\end{array}$ & $\begin{array}{l}\text { Lower incidence of } \\
\mathrm{OH} \text { related disease } \\
\text { Improve OHR-QoL } \\
\text { among children }\end{array}$ \\
\hline \multicolumn{6}{|l|}{ Education: } \\
\hline $\begin{array}{l}\text { Education } \\
\text { team } \\
\text { leader } \\
\text { Education } \\
\text { teams: } \\
\text { • Dentists } \\
\text { • } \\
\text { Hygienists } \\
\text { Location: } \\
\text { Schools }\end{array}$ & $\begin{array}{l}\text { Education sessions at } \\
\text { schools, (children, } \\
\text { mothers, teachers). } \\
\text { Participate in school } \\
\text { activities }\end{array}$ & $\begin{array}{l}\text { Knowledgeable } \\
\text { teachers, parents } \\
\text { and children }\end{array}$ & $\begin{array}{l}\text { 1. Increase number of schools in } \\
\text { the program } \\
\text { 2. Increase number of enrolled } \\
\text { children in the program } \\
\text { 3. Increased } \mathrm{OH} \text { knowledge in } \\
\text { children, teachers, and parents }\end{array}$ & $\begin{array}{l}\text { Improve } \mathrm{OH} \text { behavior of } \\
\text { children, teachers, and } \\
\text { parents }\end{array}$ & $\begin{array}{l}\text { Lower incidence of } \\
\mathrm{OH} \text { related disease } \\
\text { Improved OHR-QoL } \\
\text { among mothers' and } \\
\text { children }\end{array}$ \\
\hline
\end{tabular}


oral health knowledge, attitude, and practice, and OHRQoL.

\section{Methods \\ Study design}

This is a cross-sectional study of mother-child dyads from randomly selected public schools at Kuwait Capital School District. The University of Alberta Research Ethics Board (Protocol \#0037434), together with the Joint Committee for the Protection of Human Subjects in Research of Kuwait, approved the study protocol. Furthermore, the research was conducted in adherence with the Helsinki Declaration and the STrengthening the Reporting of OBservational studies in Epidemiology (STROBE) guidelines, and the parents/guardians of each participating child granted their written informed consent.

\section{Participants and setting}

The research was conducted for 6 months during the 2013-2014 academic year in the Capital Education/ Health Region in Kuwait. Approximately 85\% of children residing in Kuwait attend the public schools. Seven schools were randomly selected from a school list provided by the Ministry of Education Research Department. Within these seven schools, children aged 11-12 and their mothers were selected to participate. Participants were classified into two groups; SOHP and nonSOHP. The SOHP participants had been enrolled in the prevention program of the SOHP for at least 3 years. These children received, at least, one oral health education session, two applications of fluoride varnish, and (if eligible) fissure sealants. Non-SOHP participants had negative consents and had not been exposed to the program preventive activities.

A required sample size of 370 participants was calculated based on the number of children in the capital region (16,361 children) using type I error of 0.05, sampling error of 0.05 , with a goal to achieve an estimated proportion of children enrolled in the SOHP of 0.5 . A $75 \%$ positive response rate was expected, so a total of 500 consent forms were distributed.

\section{Procedure}

Trained field assistants gave a 5-min presentation to the children about the study and sent an information letter and consent form home with them for their parents to sign. Once the children's consent was obtained, field assistants administered structured questionnaires. Clinical examinations were performed at school clinics using fully equipped mobile dental chairs and sterile WHO probes and mirrors.

\section{Outcome measures}

\section{Children's dental examinations}

Clinical examinations were conducted at the school clinics to assess the normative needs of the children. The examinations, which were carried out by one calibrated examiner, were carried out in adherence to the oral health criteria recommended by the WHO. The examiner had already used the WHO criteria during the Kuwait National School Oral Health Survey (2013-2014). The examiner was blinded for the SOHP status.

The primary equipment comprised a mobile dental chair, artificial LED light, and a dental unit. High intraexamination and inter-examination consistency (kappa = 0.91 and 0.83 , respectively) were shown by the examiner. Evaluations of differences between cavitated and non-cavitated lesions followed criteria outlined in the guidelines of the International Caries Detection and Assessment System (ICDAS) (https://www.icdas.org). Additionally, the Silness-Löe plaque index [14] was used to evaluate the oral hygiene of participating children, while the PUFA index [15] measured the clinical consequences of the participants' untreated dental caries.

Decayed teeth (DT/dt), missing teeth due to caries $(\mathrm{MT} / \mathrm{mt})$, filled/restored teeth $(\mathrm{FT} / \mathrm{ft})$, DMF teeth (DMFT/dmft), and DMF surfaces (DMFS/dmfs) indices were used during the examination. Additional indices applied during the examinations included the number of sealed teeth, the number of non-cavitated teeth, the restorative care index (RI) [16] and the plaque index (PI). The PUFA index (for comprehensive oral health examination purposes) was also used.

\section{Children's OHRQoL}

To assess each participating child's oral impacts on function, lifestyle activities, general sense of well-being, and relationship with others [11], the Child Perceptions Questionnaire $\left(\mathrm{CPQ}_{11-14}\right)$, developed in Toronto, Canada by Jokovic et al. [9], was used. The questionnaire measures the following four domains and is reported in subscales: 1) oral symptoms, which are mainly pain-related; 2) functional limitations, such as difficulties encountered while eating and drinking; 3) emotional well-being, such as avoiding smiling or laughing around other people; and 4) social well-being, which involves, for instance, receiving comments from other children about his/her mouth. Overall, the questionnaire has good psychometric properties, including good internal consistency and test-retest reliability. The questionnaire can be self-administered or administered by an interviewer, with only minor differences in results [9]. In the present study, the participating children were given the $\mathrm{CPQ}_{11-14}$ self-administered form. The $\mathrm{CPQ}_{11-14}$ was translated from the original English version into Arabic, and the translation was validated by Brown and Al-Khayal [17]. 
In the questionnaire, children were asked to give their oral health a global rating and to describe the impact of their oral health status on their general well-being. The following information was used as a dependent variable in the analysis as a further indicator of OHRQoL. Across the two questions, the response options are: "Excellent" $=0$, "Very $\operatorname{good} "=1, \quad$ "Good" $=2$, "Acceptable" $=3$ and "Poor" = 4 for the global rating; and "Not at all" = 0, "Very little" = 1, "Somewhat" = 2, "A lot" = 3 and "Very much" = 4 for impact on general well-being.

Questions related to perceptions around the impacts of oral health were grouped into the following four domains: oral symptoms (6 questions), functional limitations (9 questions), emotional well-being (9 questions), and social well-being (12 questions). Participants were given five possible response options. The options were Never (0), Once or twice"(1), Sometimes (2), Often (3), and Everyday or Almost Everyday (4) to be applied within a recall period of 3 months. From these responses, domains and overall OHRQoL scores on the questionnaire were calculated by adding up the responses of the items in the domains or the whole questionnaire. Low scores indicated a better OHRQoL.

Prior to administering the questionnaire for research purposes, the Arabic-version questionnaire was given to a small group of participants as a 'pre-test'. Based on participants' responses, terms and phrases that were unclear were reworded to make them easier for the children to understand. A total of 118 questionnaires were administered twice (for a grand total of 236), with a 14-day gap between the administration of the initial pre-test and the repeat of the modified pre-test. The kappa scores for the pre-test/pre-retest questionnaires were $0.87-1.0$. The reliability results were done with children from two of the selected schools.

For the $\mathrm{CPQ}_{11-14}$ questionnaire and each subscale, Cronbach's alpha was used to quantify internal consistency, while the agreement was measured using the intra-class correlation coefficient of the repeated questionnaires. The item response rate was $100 \%$, with the results suggesting high levels of internal consistency for the questionnaire. As tested by Cronbach's alpha for the overall $\mathrm{CPQ}_{11-14}$ in the sample, reliability was 0.91. Internal consistency coefficients for emotional and social well-being subscales were excellent, measuring 0.83 and 0.81 , respectively. However, the alpha coefficient for the functional limitation subscale was acceptable (0.7), but only moderate $(0.58)$ for the oral symptoms subscale. The intra-class correlation coefficient for repeated applications of the measure was excellent at $0.89(95 \% \mathrm{CI}=0.76-0.97)$.

\section{Mothers' knowledge, attitude, practice, and OHRQoL}

Mothers were the second target population for the SOHP. According to a previously published report among the
Kuwaiti population, mothers were the main caregiver and had a high influence on children's oral health status [18]. A questionnaire on the mothers' oral health knowledge, attitude, practice and OHRQoL was used in this study. It was initially prepared in English and translated into Arabic. Then two independent translators, to check for the correctness of the messages conveyed, translated it back into English. Questions included in the questionnaire have been used in previously published studies $[19,20]$.

In addition to a section on demographics (i.e., age, educational attainment, and number of children), the questionnaire consisted of four sections. The first section included 14 questions that assessed the participants' oral hygiene knowledge. Questions were about the association between oral bacteria and systemic diseases, transmission of bacteria from parent to child, soft drinks and tooth wear, sugar intake and caries, the frequency of brushing and flossing, type of toothbrush and replacement frequency, dental check-up frequency, and use of fluoridated toothpaste. The second section consisted of six questions about attitudes toward $\mathrm{OH}$ including the importance of $\mathrm{OH}$ for overall health, the relationship between healthy diet and healthy teeth, the exclusion of unhealthy foods from school premises, the inclusion of oral health topics in the school curriculum, and mothers as oral health educators and role models for their children and students in general. The participants' oral health-related behaviors (e.g., last dental visit, brushing and flossing frequency, use of fluoridated toothpaste, etc.) were explored in the third section.

The final section asked about the participants' OHRQoL in three domains: physical, social, and psychological (self-esteem) impairments. The questions asked participants how often oral health problems affected their daily/social activities, and whether the appearance of their teeth caused them to avoid conversation.

\section{Data analysis}

The data were managed and analyzed using SPSS 21.0 software (IBM Corp., Armonk, NY, USA), and data normality were tested using the Kolmogorov-Smirnov test. The children's dental health measures and $\mathrm{CPQ}_{11-14}$ scores, and the mothers' knowledge, attitude, practice and OHRQoL mean scores were calculated and compared between children grouped by SOHP enrollment. Mean differences according to SOHP enrollment were evaluated by t-test. SOHP and non-SOHP outcomes that were significantly different were further evaluated using Poisson regression analysis that controlled for socioeconomic indicators, such as gender, the number of siblings, mother's education and mother's age. The significance level was 0.05 . To accommodate for multiple comparisons, the Bonferroni correction was used for every family of variables as follows. A $p$-value of less than 0.05 was 
considered statistically significant for oral health indicators while p-value of less than 0.013 was considered statistically significant for OHRQoL subscales and Mothers' knowledge, attitude, practice, and OHRQoL.

\section{Results}

\section{Characteristics of the studied population}

Signed consent forms with respective parent authorizations were returned by 449 participating children, giving a response rate of $88 \%$. Of these 449 , nine participants were excluded due to the presence of a systemic disorder which may affect oral health status (as reported by the parents), or due to the child's uncooperative behavior either during the clinical examination or the administration of the questionnaire.

Four hundred and forty children were included in the final sample, of which $49.3 \%$ were male. Approximately half $(46.4 \%)$ of the children were from families with $2-4$ offspring while less than a tenth $(7.7 \%)$ of the participants had no siblings. Nearly half of the mothers had earned a post-secondary degree and were 39 years of age or younger. Table 2 presents participants' demographic summary.

\section{Participants' $\mathrm{OH}$ indicators}

Mean (SD) DT/dt was 1.96 (2.24) while the mean DMFT/dmft and DMFS/dmfs were, 2.91(2.75), and 5.71 (6.94), respectively. About $23.9 \%$ of the children had a $\mathrm{DMFT} / \mathrm{dmft}$ of zero. The mean number of non-cavitated carious teeth per child was 2.34 (2.17) while the mean sealed teeth was 1.78 (2.56). The mean restorative index was $0.21(0.34)$, the plaque index was 3.59 (1.63), and the PUFA index was $0.31(0.85)$. Children's dental health status according to the demographics was reported in a previous paper [21].

The children enrolled in the SOHP had significantly lower DMFT/dmft $(P<0.001)$, DMFS/dmfs $(P<0.001)$, $\mathrm{dt} / \mathrm{Dt}(P<0.001)$ scores than non-enrolled children. In addition, they had a higher number of teeth with fissure sealants. The children's dental health status according to their SOHP enrollment is summarized in Table 3.

Having adjusted for potential confounding factors (i.e., gender, number of children, mother's age, and mothers' $\mathrm{OH}$ knowledge) in the Poisson regression analysis, we have found that enrolment in the SOHP was the only predictors for $\mathrm{DMFT} / \mathrm{dmft}$, DMFS/dmfs, DT/dt, and number of sealants (Table 4). The prevalence rate for caries/caries experience was about $50 \%$ less in children enrolled in the SOHP while the prevalence rate of sealants was 2.8 times those not enrolled in the SOHP.

\section{Children's oral health-related quality of life}

The average (SD) total $\mathrm{CPQ}_{11-14}$ score was 20.72 (16.81). The oral symptoms subscale score was 4.26 (3.32); functional limitations score was 5.40 (4.92), emotional well-being score was 5.48 (6.15), and social well-being score was 5.33 (6.05). Nearly $78 \%$ of the participating children evaluated their oral health as being excellent or very good, and 5\% evaluated it as being fair or poor. The mean overall selfevaluation of the effect of $\mathrm{OH}$ on their life was $0.69(0.95)$.

Table 2 Basic Demographics of participants according to SOHP enrolment

\begin{tabular}{|c|c|c|c|c|}
\hline Variable & Number (\%) & $\begin{array}{l}\text { SOHP } \\
N=237\end{array}$ & $\begin{array}{l}\text { None-SOHP } \\
N=203\end{array}$ & $P$-value ${ }^{* *}$ \\
\hline \multicolumn{5}{|l|}{ Children gender } \\
\hline Male & $217(49.3)$ & 114 & 103 & \multirow[t]{2}{*}{0.581} \\
\hline Female & $223(50.7)$ & 123 & 100 & \\
\hline \multicolumn{5}{|l|}{ Mother education } \\
\hline High school or less & $94(21.4)$ & 31 & 63 & \multirow[t]{4}{*}{$<0.001$} \\
\hline More than High school & $106(24.1)$ & 59 & 57 & \\
\hline College & $203(46.4)$ & 134 & 69 & \\
\hline Post-College & $27(6.1)$ & 13 & 14 & \\
\hline \multicolumn{5}{|c|}{ Number of children in the family } \\
\hline Only child & $34(7.7)$ & 20 & 14 & \multirow[t]{3}{*}{0.01} \\
\hline $2-4$ & $204(46.4)$ & 124 & 80 & \\
\hline More than 4 & $202(45.9)$ & 93 & 109 & \\
\hline \multicolumn{5}{|l|}{ Mother age ${ }^{a}$} \\
\hline Less than 40 & $227(53.0)$ & 122 & 105 & \multirow[t]{2}{*}{0.92} \\
\hline 40 and more & $201(47.0)$ & 109 & 92 & \\
\hline
\end{tabular}

SOHP School Oral Health Program

${ }^{* *}$ Chi-Square test. Significant at the level $p<0.05$

${ }^{\mathrm{a}}$ Total less than 440 due to missing information 
Table 3 Children's mean (SD) OH measures and OHRQOL scores according to SOHP enrolment

\begin{tabular}{|c|c|c|c|c|}
\hline Variable & Total & $\begin{array}{l}\text { SOHP } \\
N=237\end{array}$ & $\begin{array}{l}\text { None-SOHP } \\
N=203\end{array}$ & $P$-value ${ }^{*}$ \\
\hline \multicolumn{5}{|l|}{ Oral Health measures } \\
\hline $\mathrm{dmft} / \mathrm{DMFT}$ & $2.91(2.75)$ & $2.35(2.33)$ & $3.56(3.05)$ & $<0.001$ \\
\hline dmfs/DMFs & $5.71(6.94)$ & $4.41(5.86)$ & $7.24(7.78)$ & $<0.001$ \\
\hline $\mathrm{dt} / \mathrm{DT}$ & $1.96(2.24)$ & $1.41(1.66)$ & $2.61(2.63)$ & $<0.001$ \\
\hline $\mathrm{mt} / \mathrm{MT}$ & $0.28(0.83)$ & $0.25(0.80)$ & $0.32(0.85)$ & 0.391 \\
\hline $\mathrm{ft} . / \mathrm{FT}$ & $0.67(1.19)$ & $0.69(1.16)$ & $0.64(1.24)$ & 0.641 \\
\hline Non-cavitated lesions & $2.34(2.17)$ & $2.35(2.19)$ & $2.32(2.14)$ & 0.875 \\
\hline Fissure Sealants & $1.78(2.56)$ & $2.36(2.79)$ & $1.10(2.05)$ & $<0.001$ \\
\hline Plaque Index & $0.89(0.41)$ & $0.86(0.40)$ & $0.95(0.41)$ & 0.019 \\
\hline PUFA & $0.31(0.85)$ & $0.18(0.51)$ & $0.47(1.11)$ & 0.01 \\
\hline Restorative Index & $0.28(0.36)$ & $0.33(0.38)$ & $0.22(0.34)$ & 0.008 \\
\hline OHRQOL & Total & $\begin{array}{l}\text { SOHP } \\
N=237\end{array}$ & $\begin{array}{l}\text { None-SOHP } \\
N=203\end{array}$ & $P$-value \\
\hline Total $\mathrm{CPQ}_{11-14}$ score & $20.72(16.81)$ & $19.82(15.46)$ & $21.74(18.22)$ & 0.253 \\
\hline Oral symptoms & $4.26(3.32)$ & $4.24(3.03)$ & $4.29(3.64)$ & 0.862 \\
\hline Functional limitations & $5.41(4.92)$ & $5.23(4.44)$ & $5.59(5.43)$ & 0.457 \\
\hline Emotional well-being & $5.48(6.15)$ & $5.15(5.95)$ & $5.87(6.37)$ & 0.228 \\
\hline Social well-being & $5.33(6.05)$ & $5.06(5.97)$ & $5.64(6.14)$ & 0.321 \\
\hline
\end{tabular}

SOHP School Oral Health Program, D/d decayed, F/f filled, $M / m$ missing, $S / s$ surface, $T$ permanent teeth, $t$ primary teeth, $P U F A$ Pulp, Ulcer, Fistula, Abscess, CPQ $11-14$ Child Perception Questionnaire among 11- to 14 year-old children

*t-test with Bonferroni correction. Significant at the level $P<0.005$

*t-test with Bonferroni correction. Significant at the level $P<0.001$

Table 4 Poisson regression analysis final models predicting children $\mathrm{OH}$ indicators significantly associated with SOHP enrolments

\begin{tabular}{|c|c|c|c|c|}
\hline \multirow[t]{2}{*}{ Variables } & \multirow[t]{2}{*}{$P R^{a}$} & \multirow[t]{2}{*}{$P$-value } & \multicolumn{2}{|l|}{$95 \% \mathrm{Cl}$} \\
\hline & & & Lower limit & Upper limit \\
\hline \multicolumn{5}{|l|}{ DMFT } \\
\hline Constant & 3.613 & $<0.001$ & 2.449 & 5.330 \\
\hline Enrolment in the SOHP (No/Yes) & 0.582 & $<0.001$ & 0.510 & 0.664 \\
\hline \multicolumn{5}{|l|}{ DMFS } \\
\hline Constant & 8.120 & $<0.001$ & 6.161 & 10.702 \\
\hline Enrolment in the SOHP (No/Yes) & 0.512 & $<0.001$ & 0.466 & 0.561 \\
\hline \multicolumn{5}{|l|}{$\mathrm{DT} / \mathrm{dt}$} \\
\hline Constant & 2.728 & $<0.001$ & 1.704 & 4.366 \\
\hline Enrolment in the SOHP (No/Yes) & 0.450 & $<0.001$ & 0.385 & 0.526 \\
\hline \multicolumn{5}{|l|}{ Number of sealants } \\
\hline Constant & 0.713 & 0.226 & 0.412 & 1.233 \\
\hline Enrolment in the SOHP (No/Yes) & 2.825 & $<0.001$ & 2.157 & 3.700 \\
\hline
\end{tabular}

SOHP School Oral Health Program, D/d decayed, F/f filled, $M / m$ missing, S/s surface, $T$ permanent teeth, $t$ primary teeth ${ }^{a}$ Controlled for gender, mother's education, mother's age and number of siblings 
More than $80 \%$ of children reported that their OHRQoL were "not at all or very little" affected, and 5\% reported that it affected their life "a lot or very much." Children's OHRQoL according to demographics was previously reported [21].

There was no significant difference between SOHP-enrolled and -non-enrolled children in their total $\mathrm{CPQ}_{11-14}$ score or subscales $(P>0.013)$ (Table 3$)$.

\section{Mothers' knowledge, attitude, practice and OHRQoL}

No significant difference in mothers' $\mathrm{OH}$ knowledge, attitude, practices or OHRQoL was found between SOHP and non-SOHP groups $(\mathrm{P}>0.013)$. The mothers' mean knowledge, attitude, practice, and OHRQoL scores, according to SOHP, are summarized in Table 5.

\section{Discussion}

School oral health programs were recommended by the WHO to be a cost-effective approach to reach and promote oral health in school-aged children and to eliminate inequalities in oral health. In the present research, we investigated the effects of oral health education and preventive interventions on the dental health of schoolaged children. To assess the effectiveness (impact evaluation), we chose common variables to measure dental caries, oral hygiene, and quality of life. Overall, children enrolled in the program had better dental health (fewer caries lesion) and enrollment in the program was the main predictor of children's caries level.

The preventive interventions provided by the SOHP were evidenced-based and recommended by WHO [22]. The effectiveness of fluoride has been acknowledged in caries prevention over the past 40 years, and fluoride varnish has been the core of numerous oral health interventions in school children [23, 24]. Fissure sealant has also been recognized as an effective method for prevention of caries on occlusal surfaces in some studies [25]. Our results showed that twice a year fluoride varnish and fissure sealant as part of the school-based prevention activities were effective in reducing dental caries in children.

In Kuwait, all children in the public schools are encouraged to enroll in the SOHP. Our data indicate that

Table 5 Mothers' mean (SD) OH knowledge, attitude, practices, OHRQOL scores according to SOHP enrolment

\begin{tabular}{lllll}
\hline Variable & Total & $\begin{array}{l}\text { SOHP } \\
N=237\end{array}$ & $\begin{array}{l}\text { None-SOHP } \\
N=203\end{array}$ & $P_{\text {-value }}^{*}$ \\
\hline OH Knowledge score & $10.04(1.57)$ & $10.21(1.46)$ & $9.84(1.67)$ & 0.019 \\
OH Attitude score & $11.63(0.53)$ & $5.86(0.39)$ & $5.77(0.62)$ & 0.077 \\
OH Practices score & $13.81(2.42)$ & $13.97(2.45)$ & $13.61(2.37)$ & 0.120 \\
OHRQoL score & $0.95(1.80)$ & $0.78(1.64)$ & $1.16(1.96)$ & 0.027 \\
\hline
\end{tabular}

$\mathrm{OH}$ Oral Health, OHRQoL Oral Health Related Quality of Life, SOHP School Oral Health Program

"t-test with Bonferroni correction. Significant at the level $P<0.013$ enrollment in school-based prevention activities was associated with better dental health. Being enrolled in the SOHP influenced children's level of dental caries, the severity of the disease, and oral hygiene status. However, the program had no impact on children's OHRQoL. We previously reported that the level of dental caries had no impact on children's OHRQoL [21], a result that was inconsistent with Castro Rde et al. [26]. This inconsistency could be explained by participants' underreporting due to a lack of oral health literacy among Kuwaiti children, an area which needs more research exploration. Further investigation is required regarding the psycho-social impact of dental diseases among the Kuwaiti population.

The second target of the SOHP was the mothers. An appropriate level of oral hygiene practices is often the ultimate outcome of any oral health education/promotion program [27]. Therefore, the intention of Kuwait SOHP for mothers was also improving their oral health practices through enhancing their knowledge and attitude using the Knowledge-Attitude-Practice (KAP) model. Although mothers of children enrolled in the program had better, but not significantly, oral health knowledge, this was not reflected in their practices. SOHP policy-makers may consider adopting different educational and behavior-change models if a change is a target.

The SOHP group had better oral health status than the reported caries prevalence for all schoolchildren in various Kuwaiti governorates $[12,13]$. The overall mean of the children's $C P Q_{11-14}$ was generally better than that in a study undertaken previously in the region [17] and very similar to studies undertaken in other countries [28]. Published reports have shown that the outcome of preventive care provided through different programs varied based on the local context, and more complex interventions tend to have a lower implementation rate [29]. Many countries provide an extensive preventive regimen, including fluoride varnish, fissure sealant, and oral health education $[7,30]$ that targets only high-risk populations, and thus evaluating a public health program is a context-sensitive process. It is a challenge to capture such a program's outcomes in a quantitative study [31], because beyond quantitative measure, the context of the program goals, objectives and resources should also be considered. This could be complemented by a process evaluation (i.e., document review) and qualitative data.

The limitations of this study were twofold: the study design and the evaluation variables. Because this was a cross-sectional study, the causal link between intervention activities and dental health indicators cannot be assessed. For instance, we cannot offer conclusive evidence that fissure sealants reduced the incidence of dental caries. Moreover, the SOHP is the main proxy for free-of-charge dental services in Kuwait, and 90\% of children receive mainly therapeutic services in the program's dental center. Due to many factors confounding the relationship between 
the program activities and the dental health status, this study cannot conclude that the SOHP is an effective program in preventing dental diseases. However, a significant association was detected between enrollment in the schoolbased prevention intervention and dental health status. Such results could be introduced by selection bias given the assumption that non-SOPH children being essentially nonresponders/decliners.

\section{Conclusions}

In conclusion, the Kuwait school oral health program is a comprehensive multicomponent program that had a positive impact on children's dental health. Children enrolled in the program had lower caries levels. However, no association was detected between the program enrollment and children's OHRQoL or mothers' oral health knowledge, attitude, practice, and OHRQoL. Quality assurance and improvement approaches have to be implemented for the program to achieve better outcomes. A mixed-method approach can be used to understand the program's internaland external-context and how improvement can be accomplished.

\begin{abstract}
Abbreviations
$C P Q_{11-14:}$ Child Perception Questionnaire among 11- to 14-year-old children; dmfs/DMFS: Decayed, missing, or filled teeth; dmft/DMFT: Decayed, missing, or filled teeth; dt/DT: Decayed teeth; ft/FT: Filled teeth; mt/MT: Missing teeth; OH: Oral Health; OHRQoL: Oral Health-Related Quality of Life; PI: Plaque index; PUFA: Pulp, Ulcer, Fistula, Abscess index; SOHP: School-based Oral Health Program; STROBE guidelines: STrengthening the Reporting of OBservational studies in Epidemiology; WHO: World Health Organization
\end{abstract}

\section{Acknowledgments}

Authors gratefully thank the Ministry of Education Research Department for facilitating the data collection. This paper was part of the Ph.D. dissertation titled "Evaluation of a Long-Standing School-based Oral Health Program: A Sequential-explanatory Mixed-method Approach."

\section{Authors' contributions}

AA designed and carried out the study, analyzed the data and drafted the manuscript. SB contributed to the data collection procedure. ME contributed to study design, data analysis, and drafting the manuscript. KR, KC and RG contributed to study design and revising the manuscript. SA contributed to study design, study conduction, and reviewed the manuscript. MA contributed to study design, study conduction, data analysis and manuscript revision. All authors reviewed and approved the final version of the paper.

\section{Funding}

This study was supported by the School Oral Health Program. The program only provided logistics and manpower with no role in study design, data collection, data analysis, interpretation of the results or writing the manuscript.

\section{Availability of data and materials}

The patients' data will not be shared. However, the datasets used and analyzed during the current study are available from the corresponding author on reasonable request.

\section{Ethics approval and consent to participate}

The University of Alberta Research Ethics Board (Protocol \# 0037434), together with the Joint Committee for the Protection of Human Subjects in Research of Kuwait, approved the study protocol. The research was conducted in adherence to the Helsinki Declaration and the STROBE guidelines, and the parents/guardians of each participating child granted a written informed consent.

\section{Consent for publication}

Not applicable.

\section{Competing interests}

The authors declare that they have no competing interests.

\section{Author details}

${ }^{1}$ National School Oral Health Program, Ministry of Health, PO Box No 5338, 22064 Salmiya, Kuwait. ${ }^{2}$ College of Dental Medicine, University of New England, Portland, ME, USA. ${ }^{3}$ School of Public Health, University of Alberta, Edmonton, Alberta, Canada. ${ }^{4}$ Faculty of Extension, University of Alberta, Edmonton, Alberta, Canada. ${ }^{5}$ Faculty of Pharmacy and Pharmaceutical Sciences, University of Alberta, Edmonton, Alberta, Canada. ${ }^{6}$ School of Dentistry, Faculty of Medicine and Dentistry, University of Alberta, Edmonton, Alberta, Canada.

Received: 11 July 2018 Accepted: 21 August 2019

Published online: 02 September 2019

\section{References}

1. Cooper AM, O'Malley LA, Elison SN, Armstrong R, Burnside G, Adair P, Dugdill L, Pine C. Primary school-based behavioural interventions for preventing caries. Cochrane Database Syst Rev. 2013;5:CD009378.

2. Centers for Disease C, Prevention. Promoting oral health: interventions for preventing dental caries, oral and pharyngeal cancers, and sports-related craniofacial injuries. A report on recommendations of the task force on community preventive services. MMWR Recomm Rep. 2001;50(RR-21):1-13.

3. Alsumait A, ElSalhy M, Amin M. Long-term effects of school-based oral health program on oral health knowledge and practices and oral healthrelated quality of life. Med Princ Pract. 2015;24(4):362-8.

4. Brownson RC, Haire-Joshu D, Luke DA. Shaping the context of health: a review of environmental and policy approaches in the prevention of chronic diseases. Annu Rev Public Health. 2006;27:341-70.

5. Worthington HV, Hill KB, Mooney J, Hamilton FA, Blinkhorn AS. A cluster randomized controlled trial of a dental health education program for 10year-old children. J Public Health Dent. 2001;61(1):22-7.

6. Tai B, Du M, Peng B, Fan M, Bian Z. Experiences from a school-based oral health promotion programme in Wuhan City, PR China. Int J Paediatr Dent. 2001;11(4):286-91.

7. Ariga J, Al-Mutawa S, Nazar H. School oral health program in Kuwait. Med Princ Pract. 2014;23(Suppl 1):43-6.

8. Gherunpong S, Sheiham A, Tsakos G. A sociodental approach to assessing children's oral health needs: integrating an oral health-related quality of life (OHRQoL) measure into oral health service planning. Bull World Health Organ. 2006:84(1):36-42.

9. Jokovic A, Locker D, Stephens M, Kenny D, Tompson B, Guyatt G. Validity and reliability of a questionnaire for measuring child oral-health-related quality of life. J Dent Res. 2002;81(7):459-63.

10. Krisdapong $\mathrm{S}$, Sheiham A. Which aspects of an oral health-related quality of life measure are mainly associated with global ratings of oral health in children? Community Dent Oral Epidemiol. 2014;42(2):129-38.

11. Barbosa TS, Gaviao MB. Oral health-related quality of life in children: part II. Effects of clinical oral health status. A systematic review. Int J Dent Hyg. 2008;6(2):100-7.

12. Al-Mutawa SA, Shyama M, Al-Duwairi Y, Soparkar P. Dental caries experience of Kuwaiti kindergarten schoolchildren. Community Dent Health. 2010;27(4):213-7.

13. Al-Mutawa SA, Shyama M, Al-Duwairi Y, Soparkar P. Dental caries experience of Kuwaiti schoolchildren. Community Dent Health. 2006;23(1):31-6.

14. Silness J, Loe H. Periodontal disease in pregnancy. II: correlation between oral hygiene and periodontal condtion. Acta Odontol Scand. 1964;22:121-35.

15. Monse $B$, Heinrich-Weltzien $R$, Benzian $H$, Holmgren $C$, van Palenstein HW. PUFA--an index of clinical consequences of untreated dental caries. Community Dent Oral Epidemiol. 2010;38(1):77-82.

16. Jackson D. Measuring restorative dental care in communities. Br Dent J. 1973;134(9):385-8.

17. Brown A, Al-Khayal Z. Validity and reliability of the Arabic translation of the child oral-health-related quality of life questionnaire (CPQ11-14) in Saud Arabia. Int J Paediatr Dent. 2006;16(6):405-11. 
18. Ashkanani F, Al-Sane M. Knowledge, attitudes and practices of caregivers in relation to oral health of preschool children. Med Princ Pract. 2013;22(2):167-72.

19. Al-Ansari J, Honkala E, Honkala S. Oral health knowledge and behavior among male health sciences college students in Kuwait. BMC Oral Health. 2003;3(1):2.

20. Kressin NR, Reisine S, Spiro A 3rd, Jones JA. Is negative affectivity associated with oral quality of life? Community Dent Oral Epidemiol. 2001;29(6):412-23.

21. Alsumait A, ElSalhy M, Raine K, Cor K, Gokiert R, Al-Mutawa S, Amin M. Impact of dental health on children's oral health-related quality of life: a cross-sectional study. Health Qual Life Outcomes. 2015;13:98.

22. Petersen $\mathrm{PE}$, Kwan S. Evaluation of community-based oral health promotion and oral disease prevention--WHO recommendations for improved evidence in public health practice. Community Dent Health. 2004;21(4 Suppl):319-29

23. Paige CJ, Shahid SK. Developing and implementing a fluoride varnish programme for young children in Bradford, UK. Community Dental Health. 2014:31(1):5-8.

24. Rolnick SJ, Jackson JM, DeFor TA, Flottemesch TJ. Fluoride varnish application in the primary care setting. A clinical study. J Clin Pediatr Dent. 2015;39(4):311-4.

25. Griffin SO, Oong E, Kohn W, Vidakovic B, Gooch BF, Group CDCDSSRW, Bader J, Clarkson J, Fontana MR, Meyer DM, et al. The effectiveness of sealants in managing caries lesions. J Dent Res. 2008;87(2):169-74.

26. Castro Rde A, Portela MC, Leao AT, de Vasconcellos MT. Oral health-related quality of life of 11- and 12-year-old public school children in Rio de Janeiro. Community Dent Oral Epidemiol. 2011;39(4):336-44.

27. Morris RE, Gillespie GM, Al Za'abi F, Al Rashed B, Al Mahmeed BE. Aggressive strategic planning for oral health in Kuwait: a decade of post-war successes. East Mediterr Health $\mathrm{J}=$ La revue de sante de la Mediterranee orientale $=$ al-Majallah al-sihhiyah li-sharq al-mutawassit. 2008;14(1):216-27.

28. Foster Page LA, Thomson WM, Jokovic A, Locker D. Validation of the child perceptions questionnaire (CPQ 11-14). J Dent Res. 2005;84(7):649-52.

29. Glasgow RE, McKay HG, Piette JD, Reynolds KD. The RE-AlM framework for evaluating interventions: what can it tell us about approaches to chronic illness management? Patient Educ Couns. 2001;44(2):119-27.

30. Sagheri D, Hahn P, Hellwig E. Assessing the oral health of school-age children and the current school-based dental screening programme in Freiburg (Germany). Int J Dent Hyg. 2007;5(4):236-41.

31. Protheroe J. Communicating risk: but does it work, doctor? BMJ. 2003; 327(7428):1404.

\section{Publisher's Note}

Springer Nature remains neutral with regard to jurisdictional claims in published maps and institutional affiliations.

Ready to submit your research? Choose BMC and benefit from:

- fast, convenient online submission

- thorough peer review by experienced researchers in your field

- rapid publication on acceptance

- support for research data, including large and complex data types

- gold Open Access which fosters wider collaboration and increased citations

- maximum visibility for your research: over $100 \mathrm{M}$ website views per year

At $\mathrm{BMC}$, research is always in progress.

Learn more biomedcentral.com/submissions 